\title{
Natural history of respiratory muscle strength in spinal muscular atrophy: a prospective national cohort study
}

\author{
Esther S. Veldhoen ${ }^{1 *}{ }^{*}$, Camiel A. Wijngaarde ${ }^{2 \dagger}$, Erik H. J. Hulzebos ${ }^{3}$, Roelie M. Wösten-van Asperen ${ }^{1}$, \\ Renske I. Wadman², Ruben P. A. van Eijk2,4, Fay Lynn Asselman², Marloes Stam², Louise A. M. Otto², \\ Inge Cuppen², Feline E. V. Scheijmans ${ }^{2}$, Laura P. Verweij-van den Oudenrijn ${ }^{1}$, Bart Bartels ${ }^{3}$, Michael A. Gaytant ${ }^{5}$, \\ Cornelis K. van der Ent ${ }^{6}$ and W. Ludo van der Pol ${ }^{2}$
}

\begin{abstract}
Background: Respiratory complications are the most important cause of morbidity and mortality in spinal muscular atrophy (SMA). Respiratory muscle weakness results in impaired cough, recurrent respiratory tract infections and eventually can cause respiratory failure. We assessed longitudinal patterns of respiratory muscle strength in a national cohort of treatment-naïve children and adults with SMA, hypothesizing a continued decline throughout life.

Methods: We measured maximal expiratory and inspiratory pressure ( $\mathrm{PE}_{\max }$ and $\left.\mathrm{PI}_{\max }\right)$, Sniff Nasal inspiratory pressure (SNIP), peak expiratory flow (PEF), and peak cough flow (PCF) in treatment-naïve patients with SMA. We used mixed-models to analyze natural history patterns.
\end{abstract}

Results: We included 2172 measurements of respiratory muscle function from 80 treatment-naïve patients with SMA types 1c-3b. All outcomes were lower in the more severe phenotypes. Significant differences in PEF were present between SMA types from early ages onwards. PEF decline was linear (1-2\%/year). PEF reached values below $80 \%$ during early childhood in types $1 \mathrm{c}-2$, and during adolescence in type $3 \mathrm{a}$. $\mathrm{PE}_{\max }$ and $\mathrm{PI}_{\max }$ were severely lowered in most patients throughout life, with $P E_{\max }$ values abnormally low (i.e. $<80 \mathrm{cmH}_{2} \mathrm{O}$ ) in virtually all patients. The $P E_{\max } / \mathrm{PI}_{\max }$ ratio was $<1$ throughout life in all SMA types, indicating that expiratory muscles were most affected. All but SMA type 3b patients had a lowered PCF. Patients with types $2 \mathrm{~b}$ and $3 \mathrm{a}$ had PCF levels between 160 and $270 \mathrm{~L} / \mathrm{min}$, those with type 2a around $160 \mathrm{~L} / \mathrm{min}$ and patients with type $1 \mathrm{c}$ well below $160 \mathrm{~L} / \mathrm{min}$. Finally, SNIP was low in nearly all patients, most pronounced in more severely affected patients.

Conclusions: There are clear differences in respiratory muscle strength and its progressive decline between SMA types. We observed lower outcomes in more severe SMA types. Particularly PEF may be a suitable outcome measure for the follow-up of respiratory strength in patients with SMA. PEF declines in a rather linear pattern in all SMA types, with clear differences at baseline. These natural history data may serve as a reference for longer-term treatment efficacy assessments.

\footnotetext{
*Correspondence: E.S.Veldhoen@umcutrecht.nl

${ }^{\dagger}$ Esther S. Veldhoen and Camiel A. Wijngaarde have contributed equally to this work

1 Department of Pediatric Intensive Care, University Medical Center

Utrecht, Wilhelmina Children's Hospital, Utrecht University, PO box 85090 ,

3508 AB Utrecht, The Netherlands

Full list of author information is available at the end of the article
}

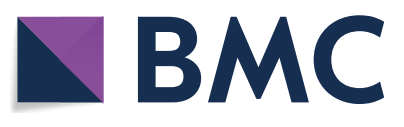

(c) The Author(s) 2022. Open Access This article is licensed under a Creative Commons Attribution 4.0 International License, which permits use, sharing, adaptation, distribution and reproduction in any medium or format, as long as you give appropriate credit to the original author(s) and the source, provide a link to the Creative Commons licence, and indicate if changes were made. The images or other third party material in this article are included in the article's Creative Commons licence, unless indicated otherwise in a credit line to the material. If material is not included in the article's Creative Commons licence and your intended use is not permitted by statutory regulation or exceeds the permitted use, you will need to obtain permission directly from the copyright holder. To view a copy of this licence, visit http://creativecommons.org/licenses/by/4.0/. The Creative Commons Public Domain Dedication waiver (http://creativeco mmons.org/publicdomain/zero/1.0/) applies to the data made available in this article, unless otherwise stated in a credit line to the data. 
Keywords: Neuromuscular, Spinal muscular atrophy, Respiratory muscle strength, Lung function, Natural history

\section{Background}

Spinal muscular atrophy (SMA) is a severe neuromuscular disease (NMD) caused by deficiency of survival motor neuron (SMN) protein, due to homozygous loss of SMN1 gene function. SMA demonstrates a broad range in clinical disease severity, which is reflected by the distinction of 4 types in the clinical classifications system [1,2]. Improved understanding of the natural history of SMA has facilitated improvements of standards for supportive care and clinical trial design [1,3-6]. Respiratory complications, such as hypoventilation and impaired secretion clearance, are the most important cause of morbidity and mortality in SMA $[1,2]$ but respiratory outcome measures have not yet been used as primary outcomes in clinical trials. This is, at least partially, caused by a lack of reference data $[7,8]$.

Respiratory muscle weakness in SMA is characterized by a rather unique pattern with predominant weakness of (mainly expiratory) intercostal muscles and relative sparing of (inspiratory) diaphragm function $[9,10]$. Respiratory muscle weakness is associated with decreased pulmonary compliance, lung underdevelopment, decreased ability to cough, and it may ultimately lead to respiratory failure [11].

Improved insights into the natural history of respiratory muscle strength could guide therapeutic management [12], improve timing of supportive care [1], and facilitate its use as an outcome measure for longer-term follow-up of patients or treatment efficacy assessments $[2,7,13,14]$. Tests of respiratory muscle strength may detect respiratory insufficiency earlier than more frequently used measurements of expiratory lung function [e.g. forced vital capacity (FVC)]. Longitudinal studies on the decline of respiratory muscle strength have been performed in other NMDs but not in SMA [15]. Therefore, we studied the natural history of respiratory muscle strength and assessed differences between SMA types in a large, population-based, treatment-naïve cohort of SMA patients.

\section{Methods}

\section{Patient characteristics and general procedures}

Patients participated in a prospective clinical cohort study on SMA. We captured patient characteristics using standardized questionnaires and physical examinations, including motor function assessments and lung function tests, as described previously $[8,16,17]$. We used patient data obtained prior to participation in a clinical trial or treatment with SMN protein augmenting drugs (i.e., 'treatment-naïve'). The local Medical Ethical Committee approved this study (09-307/NL29692.041.09) and informed consent was obtained from all participants and/ or their parents in case of minors. The reporting of this study conforms to the STROBE statement [18]. Homozygous loss of SMN1 function and SMN2 copy number were determined using multiplex ligation-dependent probe amplification (MLPA; SALSA kit P021-B1-01, MRC-Holland) [16]. Using the SMA classification system, we distinguished different SMA types as described previously (Additional File 1) [2, 6, 17, 19].

\section{Respiratory muscle strength tests}

We used respiratory muscle strength data of included patients collected during regular visits to the outpatient departments of pulmonology and the Center for Home Mechanical Ventilation at our hospital. Not all tests were performed at each visit. Data were not collected during hospital admissions, to prevent inclusion of measurements that are influenced by, for example, the presence of respiratory tract infections. For this study we used tests on expiratory strength [maximal expiratory pressure $\left(\mathrm{PE}_{\max }\right)$, peak expiratory flow (PEF), peak cough flow (PCF)] and inspiratory strength [maximal inspiratory pressure $\left(\mathrm{PI}_{\max }\right)$, sniff nasal inspiratory pressure (SNIP)]. All measurements were unassisted, i.e. not following manual compression or lung volume recruitment with frog-breathing, air stacking or mechanical insufflation-exsufflation.

$\mathrm{PE}_{\max }$ and $\mathrm{PI}_{\max }$ are non-invasive tests for the direct measurement of strength of expiratory and inspiratory muscles [15]. We measured $\mathrm{PE}_{\max }$ and $\mathrm{PI}_{\max }$ from total lung capacity and residual volume respectively, using the Geratherm Spirostik $^{\circledR}$. A nose-clip and flanged mouthpiece were used. Air leakage was prevented by a technician holding the lips. In some cases an oronasal mask was used. At least 5 repeated attempts were made. We recorded largest pressures and compared to the reference values provided by Wilson [20]. We calculated the $\mathrm{PE}_{\max } /$ $\mathrm{PI}_{\max }$ ratio to assess the relative impairment of expiratory versus inspiratory muscles $[21,22]$. SNIP is nasal pressure measured during a maximal sniff. It is a simple test of inspiratory muscle strength. We measured SNIP in both nostrils using the Micro Medical MicroRPM ${ }^{\circledR}$. Maximal nasal pressure during at least 5 sniffs, performed from Functional Residual Capacity, was compared to reference values $[23,24]$. Finally we measured maximal flow during expiration and cough: PEF and PCF. We obtained PEF values from flow-volume curve data as the maximal 
expiratory flow achieved from forced expiration following maximal lung inspiration, using the Geratherm Spirostik $^{\circledR}$ spirometer. We recorded the largest outcome from at least 3 qualitatively acceptable attempts. We reported absolute PEF values and standardized values [25, 26]. We measured PCF by maximal cough using both spirometry $\left(\right.$ Geratherm Spirostik ${ }^{\circledR}$ ) and a peak flow meter (Assess ${ }^{\circledR}$, PT-medical). We recorded the best outcome of 3 qualitatively acceptable attempts. Outcomes were reported as absolute values and compared to reference values [27, 28].

We measured all outcomes according to international guidelines [29], with patients in sitting position, without wearing corsets or braces. We used strong verbal encouragement and visual feedback to achieve maximal and reproducible test results. A resting period between tests prevented a significant influence of fatigability. All tests were performed by a small team of experienced professionals. We reported some outcomes as standardized values, i.e. as a percentage of the predicted value for age, height, weight, and sex. It is important to recognize that measuring height in SMA patients can be challenging. Tape-measured arm span was used preferably as a surrogate measure in patients unable to stand $[8,30]$.

\section{Statistical analysis}

We performed longitudinal analyses of $\mathrm{PE}_{\max }, \mathrm{PI}_{\max }$, $\mathrm{PE}_{\max } / \mathrm{PI}_{\max }$ ratio, PEF and PCF. We used a cross-sectional analyses to assess the differences in SNIP outcomes between SMA types. A longitudinal analysis was hampered due to a too limited number of observations.

For the longitudinal analyses we used all available measurements and hypothesized progressive worsening of respiratory muscle strength over time, depending on SMA type. As it was unlikely that the longitudinal patterns were completely linear, we used non-linear analyses. We fitted smoothed B-spline models with 3 knots, in which polynomial continuous regression lines were computed in-between knots [31]. For PEF we additionally assessed the longitudinal pattern with a linear mixed-effects model (LMM). The model contained age, SMA type and an interaction term of these two predictors as fixed factors. Dependency in data due to repeated measures was accounted for by a random intercept per individual. A random slope for age was added to assess differences in rates of decline between patients (as a measure of disease heterogeneity or between-patient slope variability). We evaluated whether the rate of decline over age was significantly different between SMA types using a likelihood ratio test. For cross-sectional analysis of SNIP the first measurement of all patients was used. For the cross-sectional comparisons between SMA types we hypothesized that patients with milder
SMA types would be less affected. As the assumptions of normality were met, a one-way ANOVA was used for comparisons between SMA types. A possible trend of increasing respiratory muscle strength with milder SMA types was assessed using the Jonckheere-Terpstra trend test.

\section{Results \\ Demographics}

We included 80 patients with genetically confirmed SMA types $1 \mathrm{c}-3 \mathrm{~b}$ in this study. Ages at measurements ranged from 4.1 to 66.6 years. Baseline characteristics are shown in Table 1.

\section{Peak expiratory flow (PEF)}

We analyzed 651 longitudinal measurements of PEF from 79 patients (Table 1). At baseline, PEF values differed significantly between SMA types (Fig. 1), i.e. $49 \%, 73 \%, 87 \%$ and $96 \%$ in SMA types 1c, 2a, 2b and 3a, respectively. The estimate for patients with SMA type $3 b$ is unreliable, due to a limited number of observations (Table 1). PEF decline to values $<80 \%$ was observed in early childhood in SMA types $1 \mathrm{c}-2 \mathrm{~b}$, but not until adolescence or early adulthood in type 3a. In our linear analyses the average annual rates of decline did not differ significantly between SMA types $\left(\mathrm{X}^{2}\left({ }_{4}\right)=6.2533, P=0.181\right)$. PEF declined with $0.9 \%, 2.0 \%, 1.8 \%, 1.3 \%$ and $1.4 \%$ per year in SMA type 1c, 2a, 2b, 3a, and $3 \mathrm{~b}$ respectively (model parameter estimates are shown in Additional File 2).

Non-linear analyses corroborate that PEF decline during early life is largely linear in most SMA types. In SMA type 2a this decline appears to be much faster during early childhood in comparison to children with type $2 \mathrm{~b}$. In adults with SMA types $2 \mathrm{a}, 2 \mathrm{~b}$ and $3 \mathrm{a}$ we observed relative stabilization, although the data suggest that PEF decline can still occur during adulthood. Absolute values of PEF for the different SMA types are shown in Fig. 2.

\section{Peak cough flow (PCF)}

We obtained 288 measurements from 61 patients. Longitudinal analyses are shown in Fig. 3, in which the important therapeutic thresholds of $270 \mathrm{~L} / \mathrm{min}$ [indicating vulnerability to respiratory failure during otherwise trivial respiratory tract infections (RTIs)] and $160 \mathrm{~L} / \mathrm{min}$ (indicating the boundary below which secretion clearance becomes ineffective) are marked [32].

PCF was lowest in SMA type 1c, with values $<160 \mathrm{~L} /$ min throughout life. After early childhood, patients with SMA type 2 reached values between 160 and $270 \mathrm{~L} / \mathrm{min}$, with clear differences between types $2 \mathrm{a}$ and $2 \mathrm{~b}$. Median PCF remained around $160 \mathrm{~L} / \mathrm{min}$ in type 2 a during adolescence and early adulthood, whereas in type $2 \mathrm{~b}$ median PCF steadily increased until (early) adulthood. Patients 
Table 1 Baseline characteristics

\begin{tabular}{|c|c|c|c|c|c|c|}
\hline & Total number (n) & SMA type 1c (n) & SMA type $2 \mathrm{a}(n)$ & SMA type $2 b(n)$ & SMA type $3 a(n)$ & SMA type $3 b(n)$ \\
\hline \multicolumn{7}{|l|}{ Participants } \\
\hline Patients & 80 & 6 & 32 & 22 & 16 & 4 \\
\hline Female gender & 52 & 3 & 20 & 14 & 12 & 3 \\
\hline \multicolumn{7}{|l|}{ SMN2 copies } \\
\hline 2 & 4 & 1 & 1 & 1 & 1 & - \\
\hline 3 & 66 & 5 & 29 & 18 & 12 & 2 \\
\hline 4 & 10 & - & 2 & 3 & 3 & 2 \\
\hline \multicolumn{7}{|c|}{ Tests of respiratory muscle strength } \\
\hline \multicolumn{7}{|l|}{ Peak expiratory flow (PEF) } \\
\hline Patients & 79 & 6 & 31 & 22 & 16 & 4 \\
\hline Tests & 651 & 67 & 297 & 156 & 114 & 17 \\
\hline Follow-up (years) [IQR] & $6.7[1.2-12]$ & $6.8[3.5-8.2]$ & $7.3[1.3-12.2]$ & $6.2[1.2-11.8]$ & $2.1[0.4-9.8]$ & $11.1[7.7-15.3]$ \\
\hline \multicolumn{7}{|l|}{ Peak cough flow (PCF) } \\
\hline Patients & 61 & 4 & 27 & 19 & 9 & 2 \\
\hline Tests & 288 & 27 & 144 & 76 & 35 & 6 \\
\hline Follow-up (years) [IQR] & $3.6[0.3-8.1]$ & $6.6[4.7-8.8]$ & $5.6[0.8-7.9]$ & $3.4[0.3-8.3]$ & $0.9[0.0-2.2]$ & $2.0[1.0-3.0]$ \\
\hline \multicolumn{7}{|c|}{ Maximum expiratory pressure $(P E)_{\max }$} \\
\hline Patients & 75 & 6 & 28 & 22 & 15 & 4 \\
\hline Tests & 586 & 59 & 261 & 148 & 102 & 16 \\
\hline Follow-up (years) [IQR] & $5.8[1.1-10.2]$ & $4.4[1.8-7.1]$ & $6.1[1.5-11.2]$ & $6.2[1.0-11.5]$ & $3.0[0.4-9.2]$ & $7.3[4.9-9.6]$ \\
\hline \multicolumn{7}{|c|}{ Maximum inspiratory pressure (PI) $\max$} \\
\hline Patients & 76 & 6 & 28 & 22 & 16 & 4 \\
\hline Tests & 590 & 60 & 263 & 148 & 103 & 16 \\
\hline Follow-up (years) [IQR] & $6.3[1.1-10.6]$ & $6.7[3.5-7.6]$ & $6.6[1.5-13.0]$ & $6.2[1.0-11.5]$ & $2.5[0-9.2]$ & $7.3[4.9-9.6]$ \\
\hline \multicolumn{7}{|l|}{$P E_{\max } / P I_{\max }$ ratio } \\
\hline Patients & 75 & 6 & 28 & 22 & 15 & 4 \\
\hline Tests & 582 & 57 & 259 & 147 & 103 & 16 \\
\hline Follow-up (years) [(IQR] & $5.8[1.1-10.2]$ & $4.4[1.8-7.1]$ & $6.1[1.5-11.2]$ & $6.2[1.0-11.5]$ & $3.0[0.4-9.2]$ & $7.3[4.9-9.6]$ \\
\hline \multicolumn{7}{|c|}{ Sniff inspiratory pressure (SNIP) } \\
\hline Patients & 57 & 3 & 22 & 19 & 11 & 2 \\
\hline
\end{tabular}

$I Q R$ interquartile range, $n$ number, $P C F$ peak cough flow, $P E F$ peak expiratory flow, $P E_{\text {max }}$ maximal expiratory pressure, $P I_{\text {max }}$ maximal inspiratory pressure, $S N I P$ sniff nasal inspiratory pressure

with SMA type 3a had higher PCF values from earlier ages onwards in comparison to type $2 \mathrm{~b}$, but median values were still well below normal. The limited available data obtained from patients with type $3 \mathrm{~b}$ indicate that even for these more mildly affected patients, PCF values may decrease in aging individuals.

\section{Maximal expiratory pressure $\left(\mathrm{PE}_{\max }\right)$}

We analyzed 586 measurements from 75 patients (Fig. 4), showing lower $P E_{\max }$ values from early childhood onwards in patients with SMA types 1c-3a compared to the reference population, where $P E_{\max }$ values are usually $\geq 80 \mathrm{cmH}_{2} \mathrm{O}$ during adulthood [20]. Patients with type $1 \mathrm{c}$ had severely lowered $\mathrm{PE}_{\max }$, without improvements with increasing age. $\mathrm{PE}_{\max }$ in types $2 \mathrm{a}$ and $2 \mathrm{~b}$ increased in adolescence to $40-50 \mathrm{cmH}_{2} \mathrm{O}$. It is noteworthy that, despite limited data, all $\mathrm{PE}_{\max }$ values from patients with SMA type $3 \mathrm{~b}$ were $<80 \mathrm{cmH}_{2} \mathrm{O}$ and suggestive of a decline later in life.

\section{Maximal inspiratory pressure $\left(\mathrm{PI}_{\text {max }}\right)$}

We assessed $\mathrm{PI}_{\max }$ longitudinally using 590 measurements from 76 patients (Fig. 5). Large intra- and interindividual differences were present, in accordance with findings in the reference population [33]. Overall, $\mathrm{PI}_{\max }$ was most affected in type 1c without improvements with increasing age. In patients with type $2 \mathrm{a}, \mathrm{PI}_{\max }$ increased to approximately $50-60 \mathrm{cmH}_{2} \mathrm{O}$ in adolescence. By contrast, patients with SMA type $2 \mathrm{~b}$ reached $\mathrm{PI}_{\max }$ values $>80 \mathrm{cmH}_{2} \mathrm{O}$ during adulthood. Patients with type 3 a had a similar pattern, although in our cohort they did decline well below $80 \mathrm{cmH}_{2} \mathrm{O}$ from approximately 


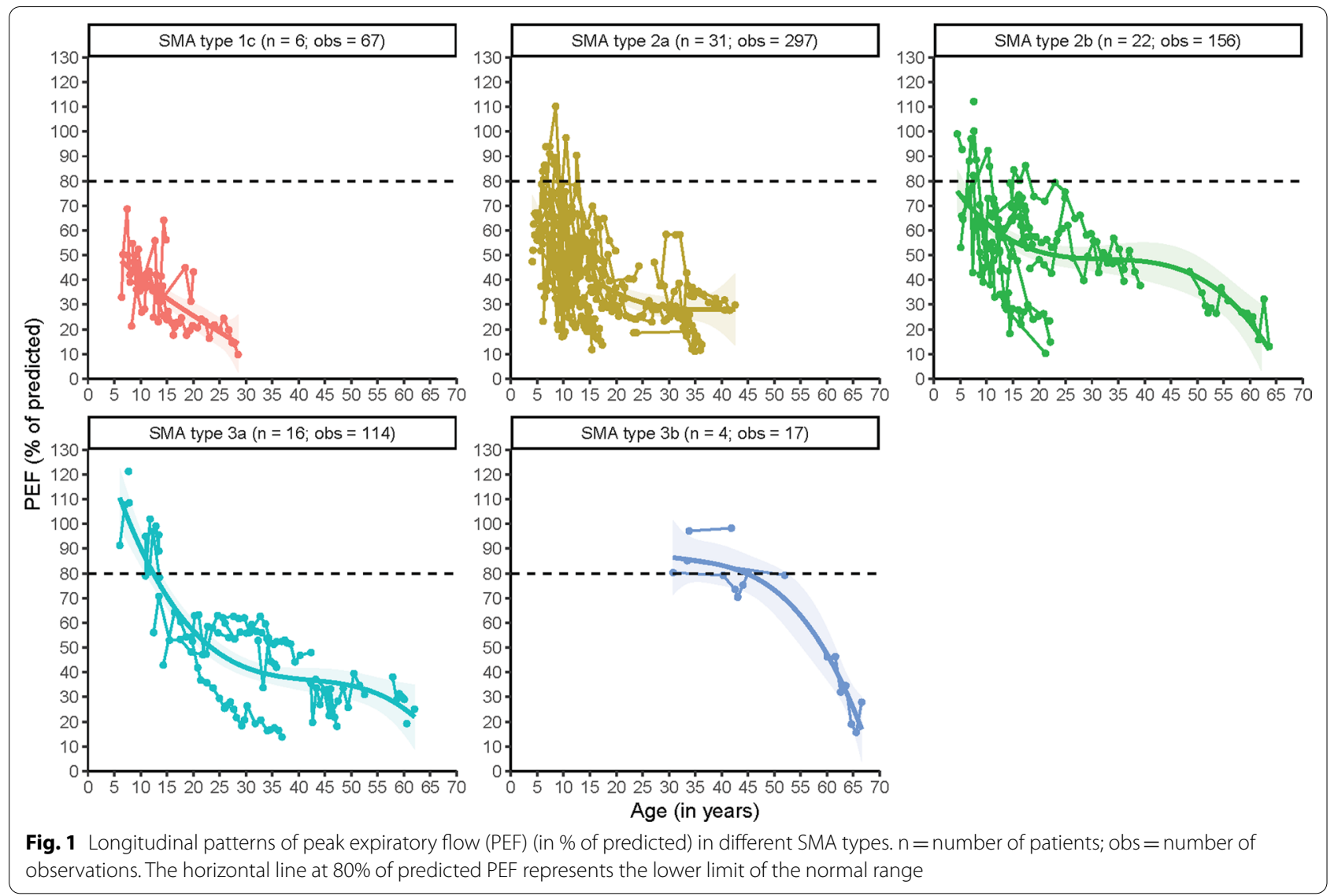

30 years onwards. The limited number of observations precludes definite conclusions for SMA type $3 \mathrm{~b}$.

\section{$\mathrm{PE}_{\text {max }} / \mathrm{PI}_{\text {max }}$ ratio}

We obtained 582 measurements from 75 patients. Figure 6 summarizes the longitudinal course, with a median ratio $<1$ for all SMA types, except for a small number of older patients with SMA type 3a (but not type 3b).

\section{Sniff nasal inspiratory pressure (SNIP)}

We used the available SNIP data from 57 patients [median age: 12.9 years (IQR 9.9-29.0)]. SNIP was not statistically different between SMA types $(\mathrm{F}(4,52)=2.219, P=0.080)$. Median SNIP was 33, 44, 59, 58 and $55 \mathrm{cmH}_{2} \mathrm{O}$ in SMA types $1 \mathrm{c}, 2 \mathrm{a}, 2 \mathrm{~b}, 3 \mathrm{a}$, and $3 \mathrm{~b}$, respectively. We found a significant trend of increasing SNIP values with milder types $(\mathrm{JT}=743, P=0.0053)$. Importantly, virtually all SNIP outcomes were below $75 \mathrm{cmH}_{2} \mathrm{O}$, which is considered the lower limit of normal (Fig. 7).

\section{Discussion}

Here, we present natural history data on the longitudinal course of respiratory muscle strength in treatment-naïve patients with SMA. We show that there are clear differences in respiratory muscle strength between SMA types with a progressive decline. In general, measurements of respiratory muscle strength are most affected in the more severe SMA types. Based upon our data, particularly PEF may be a suitable outcome measure for follow-up of patients with SMA.

Progressive respiratory muscle weakness is the most important cause of morbidity and mortality in patients with SMA [1, 2] and contributes to the increasing dependency on mechanical ventilation of patients with SMA types 1 and 2 [34]. The absence of respiratory function measures as a primary outcome in the pivotal clinical trials of recently introduced genetic therapies for SMA is at least partially explained by the scarcity of reference data $[4,5]$. Recent studies on the effect of nusinersen treatment in adult patients have focussed on motor scores and indicate that identification of the 'ideal' outcome parameter, reflecting both worsening or improvement in motor function at all grades of disease severity, might not be feasible. This has contributed to the advice 


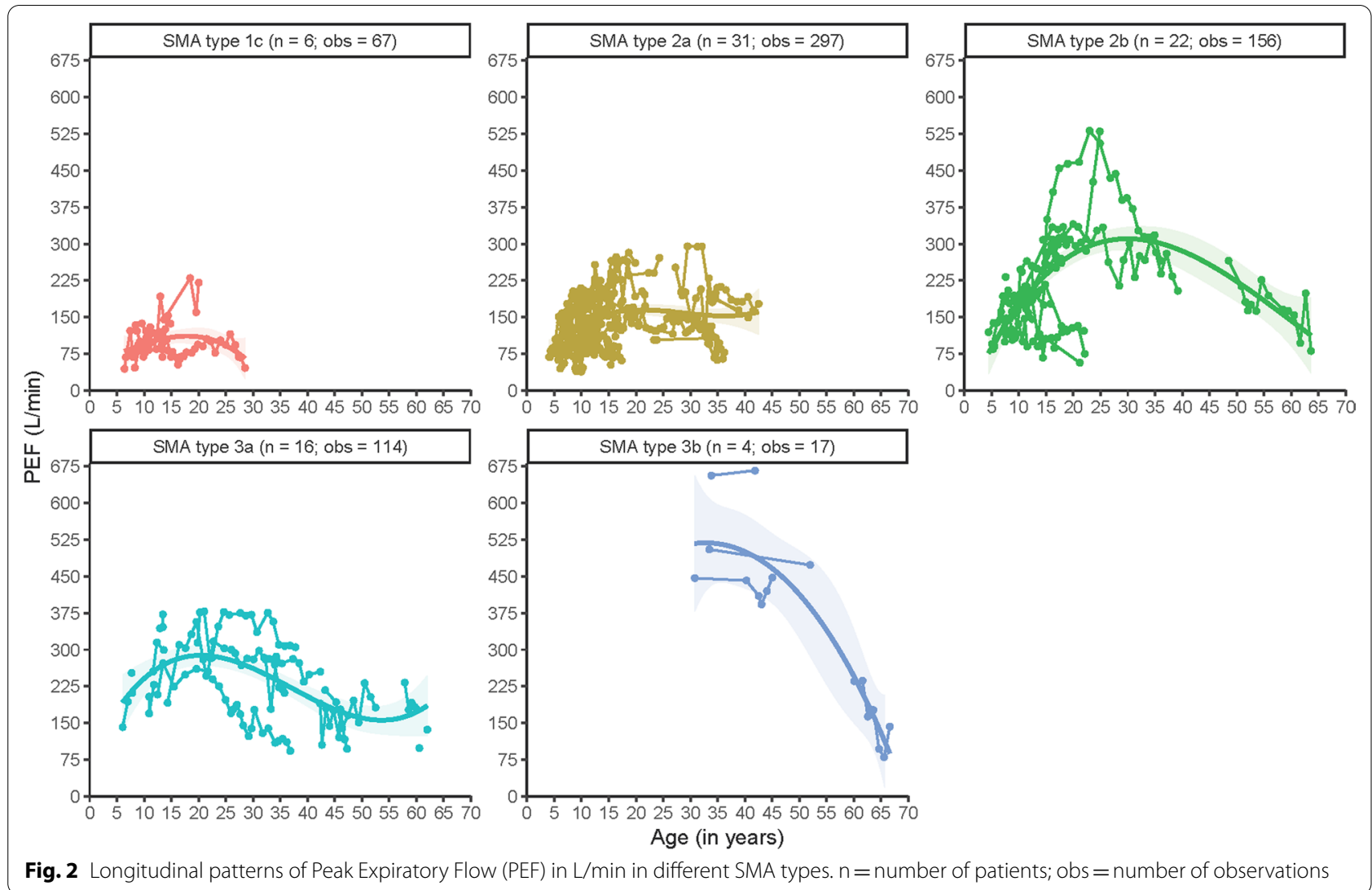

that future studies should focus on the long-term effect of nusinersen on other motor-related functions such as ventilation [35]. We recently published a large body of natural history data on lung function in SMA [8], but these spirometry endpoints may be affected by factors that are independent of respiratory muscle dysfunction [36]. Respiratory muscle strength may be an even more appropriate outcome measure [36].

$\mathrm{PE}_{\max }$ and $\mathrm{PI}_{\max }$ were severely affected in SMA types $1 \mathrm{c}-3 \mathrm{a} . \mathrm{PE}_{\max }$ may be the most suitable outcome of these two, as expiratory muscle function is predominantly affected in patients with $\mathrm{SMA}[9,10]$. Interestingly, $\mathrm{PE}_{\max }$ was low in patients with SMA type 3a from early ages on, whilst we have previously shown that lung volumes in these patients remain normal at least until (early) adulthood [8]. Based on these data, we believe $\mathrm{PE}_{\max }$ is a sensitive screening parameter to detect respiratory muscle weakness in SMA patients.

Our findings corroborate the results of some previous cross-sectional studies indicating decreased $\mathrm{PE}_{\max }$ and $\mathrm{PI}_{\max }$ with normal lung volumes in patients with SMA types 2 and $3[15,21]$, although different results in two other small studies have also been reported $[9,37]$.

SNIP has been proposed as an alternative or complementary test to $\mathrm{PI}_{\max }$. It measures inspiratory strength and normal values exclude inspiratory muscle weakness $[32,38]$. In our cohort, SNIP was abnormally lowered in virtually all patients without significant differences between SMA types, although a trend of decreasing SNIP values with more severe phenotypes was present. Our observations are in accordance with the recent work of Kapur [37]. Although SNIP is easy to perform, it may underestimate inspiratory muscle strength in case of nasal obstruction or severe respiratory muscle weakness [38], which may be present from young ages onwards in patients with SMA types 1 and 2. Even though strong correlations between SNIP, PI ${ }_{\max }$ and vital capacity have been shown [28], we believe it may be less suited to discriminate between SMA types or as an outcome measure for longitudinal follow-up.

In the absence of bronchial obstruction, PEF reflects maximal expiratory flow [12, 39]. We observed differences at baseline between SMA types and a rather linear decline of PEF in most types over time, resembling the course of FVC in patients with SMA [8]. As the average annual PEF decline did not differ significantly between SMA types, SMA types are primarily separated by differences already present at baseline or occurring very early in life. The observed pattern of relative stabilization in adults with SMA types 2 and 3a could be caused 


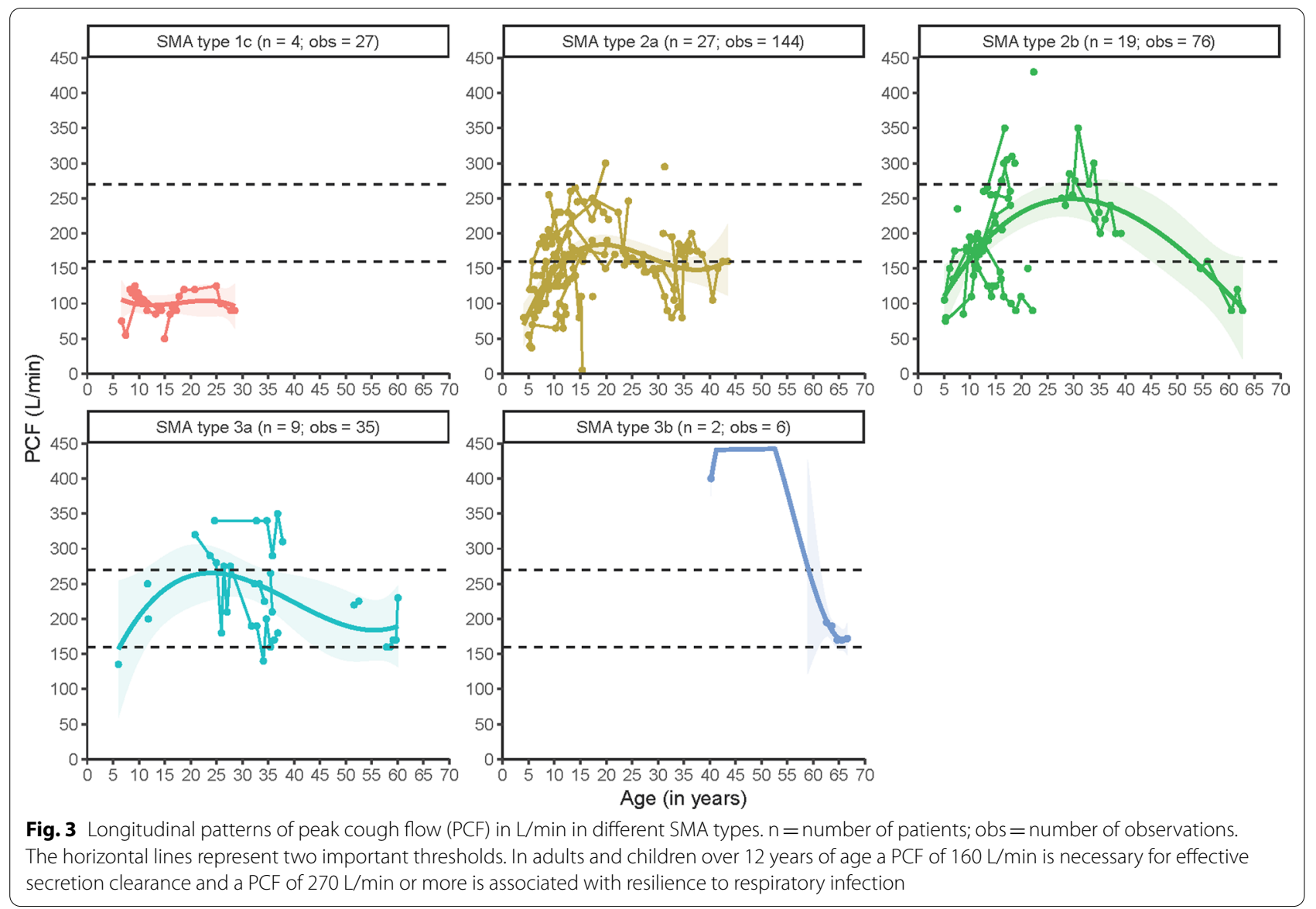

by relative disease stabilization, but we believe it is more likely the consequence of either a floor effect due to difficulties with quantification of very low PEF values or loss to follow-up of most severely affected patients due to death or initiation of invasive mechanical ventilation. Based upon our findings, PEF may be used as an outcome measure for SMA in future studies, as has also been suggested for Duchenne Muscular Dystrophy [40].

Coughing is essential for airway clearance and requires coordinated use of both inspiratory and expiratory muscles, which can be assessed by PCF [28]. PCF in SMA patients had previously only been studied in small cohorts [37]. In our study, nearly all patients had a $\mathrm{PCF}<270 \mathrm{~L} / \mathrm{min}$. In SMA type $1 \mathrm{c}$ and a large number of patients with type 2 PCF was even $<160 \mathrm{~L} / \mathrm{min}$. Since low PCF is associated with an increased occurrence of RTIs, PCF could represent a clinically meaningful endpoint for trials.

Our work has important strengths and expands the scarce natural history data on respiratory strength in patients with SMA. First, we investigated a range of measurements reflecting respiratory muscle strength in a large population-based cohort, covering a broad spectrum of SMA severity and a wide age range. Secondly, the large cohort allowed for analyses to assess differences between SMA types. We studied several tests of respiratory muscle weakness as it is known that combining these tests increases diagnostic precision [41]. Finally, to overcome the risk of including inaccurate data from weaker patients, especially young children, professionals experienced in performing these tests in pediatric and adult patients with NMDs conducted all tests.

The generally broad confidence intervals around both intercepts and slopes are a limitation of our work. It reflects the uncertainty of the predicted longitudinal patterns. This can partly be explained by the inability of young children to reliably perform these tests, but also the limited number of observations at older ages for some of the SMA types. The limited number of elderly patients in our cohort is possibly partly explained by SMA-related death or loss to follow-up. However, we do not believe that this changes our conclusion that the general pattern of respiratory muscle strength is one of decline over time. Finally, our study lacks an assessment of possible confounders, such as severity of (corrected) scoliosis, use of airway clearance techniques, or 

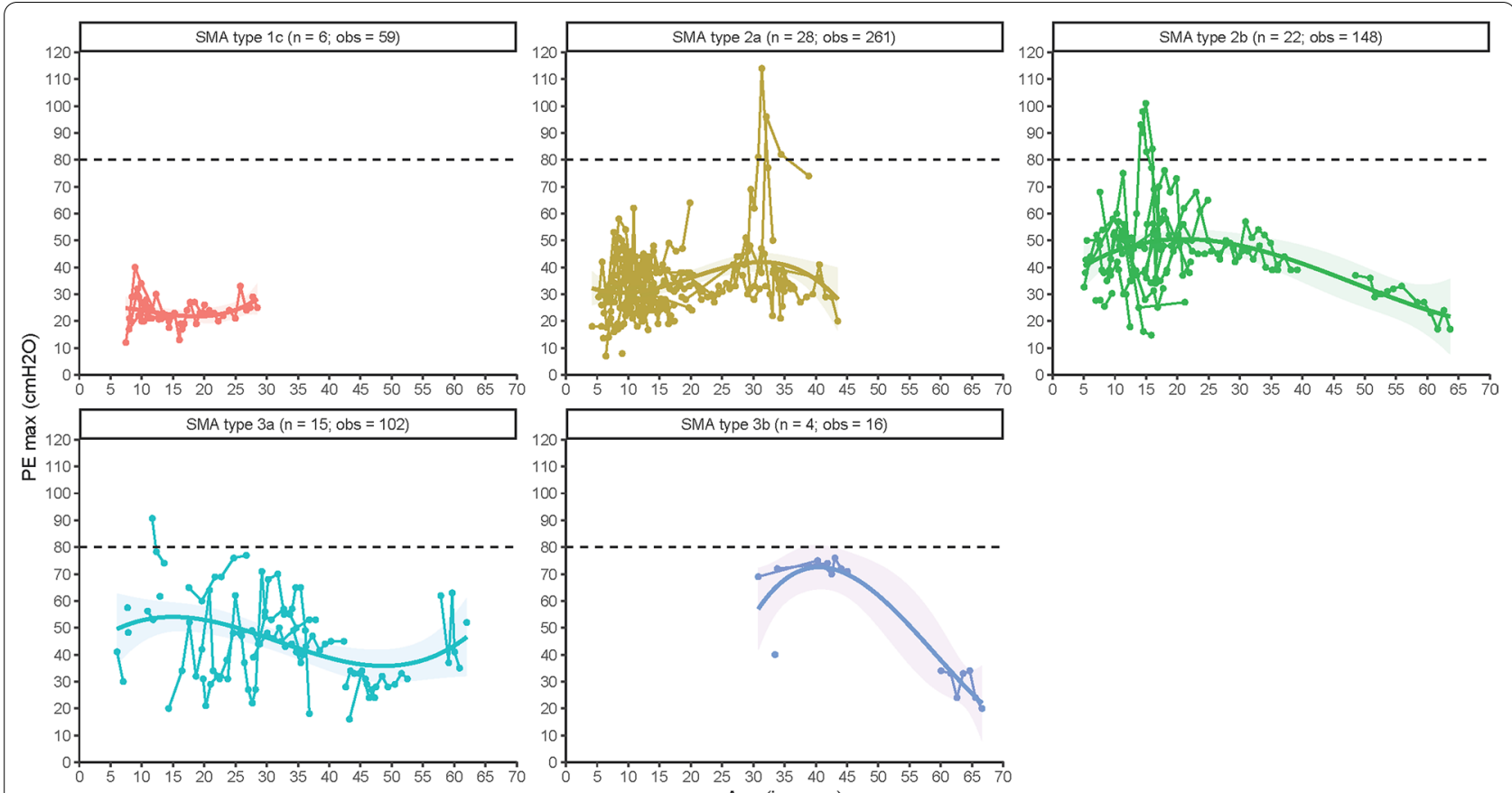

Fig. 4 Longitudinal patterns of maximal expiratory pressure $\left(\mathrm{PE}_{\max }\right)$ in $\mathrm{CmH}_{2} \mathrm{O}$ in different $\mathrm{SMA}$ types. $\mathrm{n}=$ number of patients; obs $=$ number of observations. The horizontal line represents the lower limit of normal $\mathrm{PE}_{\max }$
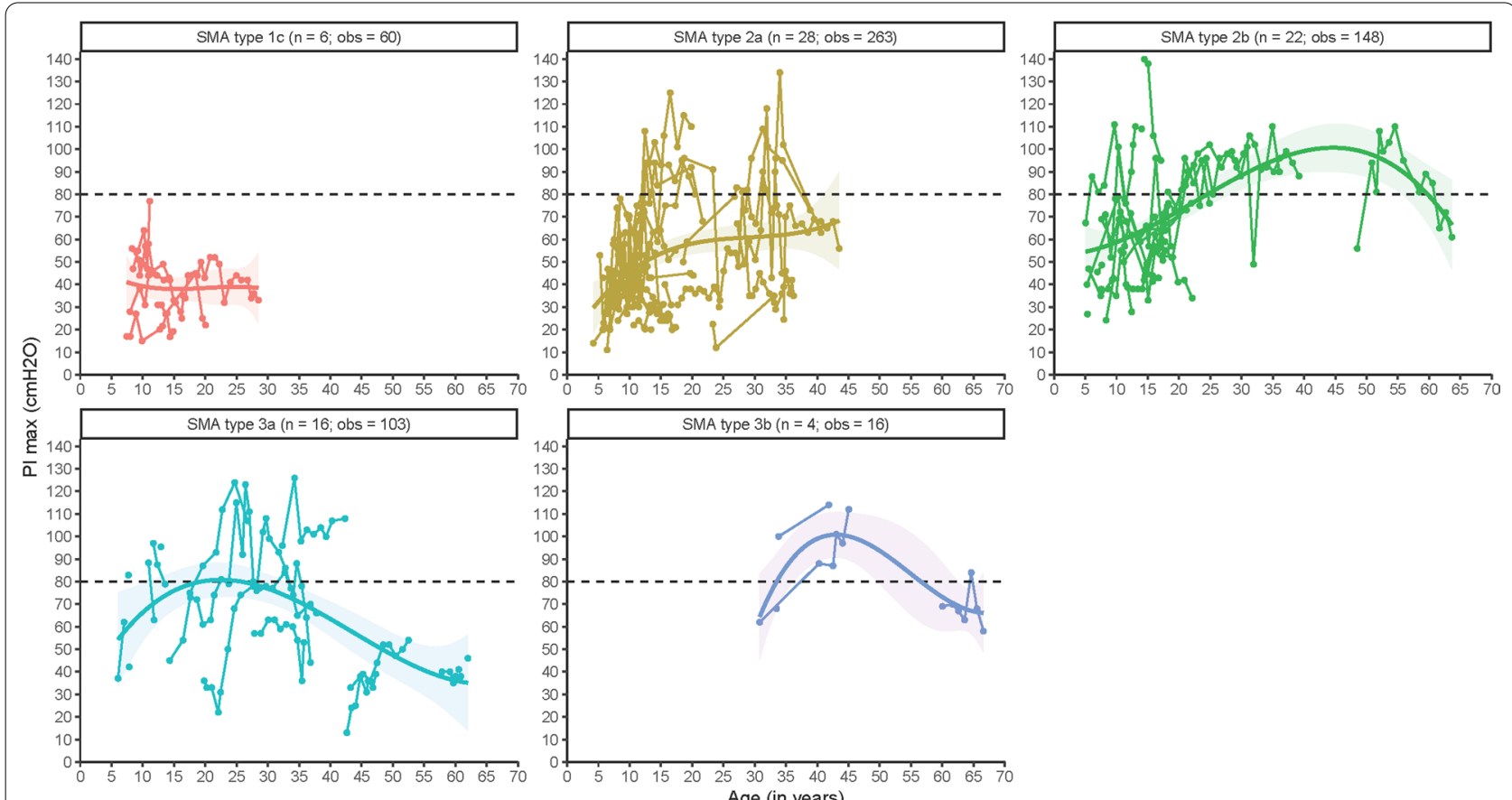

Fig. 5 Longitudinal patterns of maximal inspiratory pressure $\left(\mathrm{PI}_{\max }\right)$ in $\mathrm{cmH}_{2} \mathrm{O}$ in different $\mathrm{SMA}$ types. $\mathrm{n}=$ number of patients; obs $=$ number of observations. The horizontal line represents the lower limit of normal $\mathrm{PI}_{\max }$ 

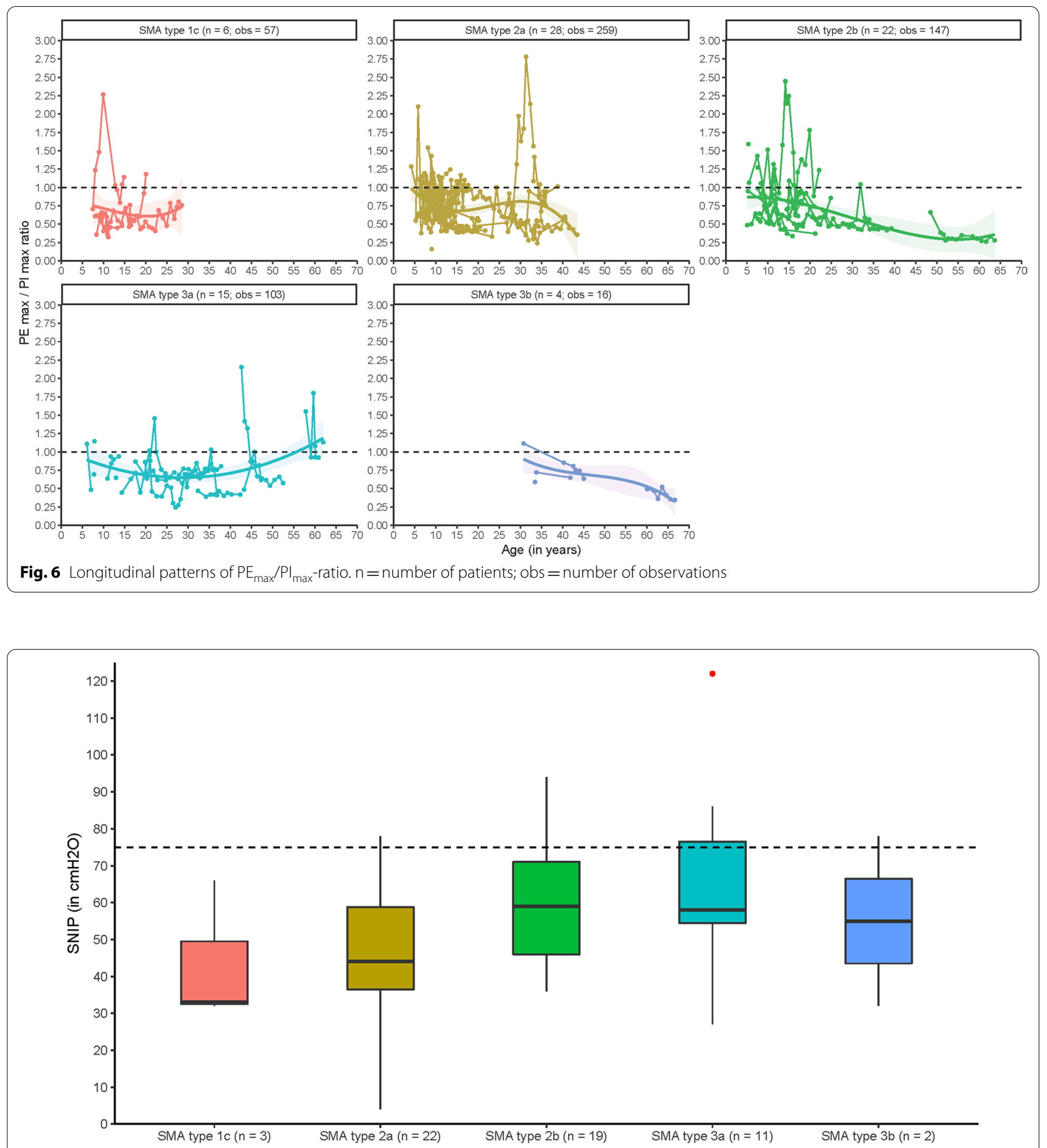

Fig. 7 Sniff nasal inspiratory pressure (SNIP) for the different SMA types. Boxplot of median SNIP values for each SMA type; red dots indicate outliers

mechanical ventilation. However, we consider this less important as our study focuses on the natural history of SMA with treatment according to the standards of care $[1,6]$.

\section{Conclusion}

There are clear differences in respiratory muscle strength and its progressive decline between SMA types. In general, measurements of respiratory muscle strength are most affected in the more severe SMA types. PEF 
declines in a rather linear pattern in all SMA types and is among the most suitable measures to be used for the longer-term follow up of patients and treatment efficacy assessments.

\section{Supplementary Information}

The online version contains supplementary material available at https://doi. org/10.1186/s13023-022-02227-7.

Additional file 1 Classification of SMA types.

Additional file $\mathbf{2}$ Standardized PEF (in \%) stratified by SMA type: model parameters estimates.

\section{Acknowledgements}

We thank all patients with SMA who have been participating in our ongoing study and the Dutch organization for Neuromuscular Diseases (Spierziekten Nederland) for their continuing support of our research.

\section{Authors' contributions}

ESV: Design and conceptualization of the study; acquisition of data; data analysis and interpretation; drafting and revising the manuscript for intellectual content. CAW: Design and conceptualization of the study; acquisition of data; data analysis and interpretation; drafting and revising the manuscript for intellectual content. EHJH: Design of the study; data interpretation; revising the manuscript for intellectual content. RMWA: Design of the study; data interpretation; revising the manuscript for intellectual content. RIW: Acquisition of data; data interpretation; revising the manuscript for intellectual content. RPAE: Data analysis and interpretation; revising the manuscript for intellectual content. FLA: Acquisition of data; data interpretation; revising the manuscript for intellectual content. MS: Acquisition of data; data interpretation; revising the manuscript for intellectual content. LAMO: Acquisition of data; data interpretation; revising the manuscript for intellectual content. IC: Acquisition of data; data interpretation; revising the manuscript for intellectual content. FEVS: Acquisition of data; data interpretation; revising the manuscript for intellectual content. LPVO: Data interpretation; revising the manuscript for intellectual content. BB: Data interpretation; revising the manuscript for intellectual content. MG: Data interpretation; revising the manuscript for intellectual content. CKE: Design and conceptualization of the study; data interpretation; revising the manuscript for intellectual content. WLP: Design and conceptualization of the study; acquisition of data; data analysis and interpretation; drafting and revising the manuscript for intellectual content. All authors read and approved the final manuscript.

\section{Funding}

Our work was financially supported by the Prinses Beatrix Spierfonds (WAR 08-24, 13-07, and 14-26) and stichting Spieren voor Spieren.

\section{Availability of data and materials}

The presented model summary statistics allow full reproduction of all LMMS. Additional data supporting our findings are available upon reasonable request.

\section{Declarations}

\section{Ethics approval and consent to participate}

The Medical Ethical Committee of the University Medical Center Utrecht approved this study (09-307/NL29692.041.09) and informed consent was obtained from all participants and/or their parents in case of minors.

\section{Consent for publication}

Not applicable.

\section{Competing interests}

W. Ludo van der Pol was member of the scientific advisory boards of Biogen and Avexis.

\section{Author details}

${ }^{1}$ Department of Pediatric Intensive Care, University Medical Center Utrecht, Wilhelmina Children's Hospital, Utrecht University, PO box 85090, 3508 AB Utrecht, The Netherlands. ${ }^{2}$ Department of Neurology, UMC Utrecht Brain Center, University Medical Center Utrecht, Utrecht University, Utrecht, The Netherlands. ${ }^{3}$ Child Development and Exercise Center, Wilhelmina Children's Hospital, University Medical Center Utrecht, Utrecht University, Utrecht, The Netherlands. ${ }^{4}$ Biostatistics and Research Support, Julius Center for Health Sciences and Primary Care, University Medical Center Utrecht, Utrecht University, Utrecht, The Netherlands. ${ }^{5}$ Department of Pulmonology, Center of Home Mechanical Ventilation, University Medical Center Utrecht, Utrecht University, Utrecht, The Netherlands. ${ }^{6}$ Department of Pediatric Pulmonology, Wilhelmina Children's Hospital, Member of ERN-LUNG, University Medical Center Utrecht, Utrecht, The Netherlands.

Received: 22 July 2021 Accepted: 6 February 2022 Published online: 21 February 2022

\section{References}

1. Finkel RS, Mercuri E, Meyer OH, Simonds AK, Schroth MK, Graham RJ, et al. Diagnosis and management of spinal muscular atrophy: Part 2: pulmonary and acute care; medications, supplements and immunizations; other organ systems; and ethics. Neuromuscul Disord. 2018;28(3):197-207.

2. Mercuri E, Bertini E, lannaccone ST. Childhood spinal muscular atrophy: controversies and challenges. Lancet Neurol. 2012;11(5):443-52.

3. Finkel RS, Mercuri E, Darras BT, Connolly AM, Kuntz NL, Kirschner J, et al. Nusinersen versus sham control in infantile-onset spinal muscular atrophy. N Engl J Med. 2017;377(18):1723-32.

4. Mercuri E, Darras BT, Chiriboga CA, Day JW, Campbell C, Connolly AM, et al. Nusinersen versus sham control in later-onset spinal muscular atrophy. N Engl J Med. 2018;378(7):625-35.

5. Mendell JR, Al-Zaidy S, Shell R, Arnold WD, Rodino-Klapac LR, Prior TW, et al. Single-dose gene-replacement therapy for spinal muscular atrophy. N Engl J Med. 2017;377(18):1713-22.

6. Mercuri E, Finkel RS, Muntoni F, Wirth B, Montes J, Main M, et al. Diagnosis and management of spinal muscular atrophy: Part 1: recommendations for diagnosis, rehabilitation, orthopedic and nutritional care. Neuromuscul Disord. 2018;28(2):103-15.

7. Darras BT, De Vivo DC. Precious SMA natural history data: a benchmark to measure future treatment successes. Neurology. 2018;91 (8):337-9.

8. Wijngaarde CA, Veldhoen ES, Van Eijk RPA, Stam M, Otto LAM, Asselman $\mathrm{FL}$, et al. Natural history of lung function in spinal muscular atrophy. Orphanet J Rare Dis. 2020;15(1):88.

9. Nicot F, Hart N, Forin V, Le Boulé M, Clément A, Polkey Ml, et al. Respiratory muscle testing: a valuable tool for children with neuromuscular disorders. Am J Respir Crit Care Med. 2006;174(1):67-74.

10. Schroth MK. Special considerations in the respiratory management of spinal muscular atrophy. Pediatrics. 2009;123(S4):S245-249.

11. Lissoni A, Aliverti A, Molteni F, Bach JR. Spinal muscular atrophy: kinematic breathing analysis. Am J Phys Med Rehabil. 1996;75:332-9.

12. Fauroux B, Khirani S. Neuromuscular disease and respiratory physiology in children: putting lung function into perspective. Respirology. 2014;19(6):782-91.

13. lannaccone ST, Rabb K, Carman D, Gordon J, Harris K, Morton A, et al. Outcome measures for pediatric spinal muscular atrophy. Arch Neurol. 2002;59(9):1445-50.

14. Kaufmann $P$, lannaccone ST. Clinical trials in spinal muscular atrophy. Phys Med Rehabil Clin N Am. 2008;19(3):653-60.

15. Wenninger S, Stahl K, Wirner C, Einvag K, Thiele S, Walter MC, et al. Utility of maximum inspiratory and expiratory pressures as a screening method for respiratory insufficiency in slowly progressive neuromuscular disorders. Neuromuscul Disord. 2020;30(8):640-8.

16. Wadman RI, Stam M, Gijzen M, Lemmink HH, Snoeck IN, Wijngaarde CA, et al. Association of motor milestones, SMN2 copy and outcome in spinal muscular atrophy types 0-4. J Neurol Neurosurg Psychiatry. 2017:88(4):365-7.

17. Wijngaarde CA, Stam M, Otto LAM, Bartels B, Asselman FL, van Eijk RPA, et al. Muscle strength and motor function in adolescents and adults with spinal muscular atrophy. Neurology. 2020;95(14):e1988-1998. 
18. von Elm E, Altman DG, Egger M, Pocock SJ, Gøtzsche PC, Vandenbroucke $J$. The strengthening the reporting of observational studies in epidemiology (STROBE) statement: guidelines for reporting observational studies. J Clin Epidemiol. 2008;61(4):344-9.

19. Zerres K, Schöneborn SR. Natural history in proximal spinal muscular atrophy: clinical analysis of 445 patients and suggestions for a modification of existing classifications. Arch Neurol. 1995;52(5):518-23.

20. Wilson SH, Cooke NT, Edwards RHT, Spiro SG. Predicted normal values for maximal respiratory pressures in caucasian adults and children. Thorax. 1984;39(7):535-8.

21. Carter GT, Abresch RT, Fowler WM, Johnson ER, Kilmer DD, McDonald CM. Spinal muscular atrophy. Am J Phys Med Rehabil. 1995;74(5 Suppl):S150-159.

22. Fregonezi GAF, Resqueti VR, Güell R, Pradas J, Casan P, Augusto De Freitas Fregonezi $\mathrm{G}$, et al. Effects of 8-week, interval-based inspiratory muscle training and breathing retraining in patients with generalized myasthenia gravis. Chest. 2005;128(3):1524-30.

23. Héritier F, Rahm F, Pasche P, Fitting JW. Sniff nasal inspiratory pressure: a noninvasive assessment of inspiratory muscle strength. Am J Respir Crit Care Med. 1994:150(6 Pt 1):1678-83.

24. Stefanutti D, Fitting JW. Sniff nasal inspiratory pressure: reference values in Caucasian children. Am J Respir Crit Care Med. 1999;159(1):107-11.

25. Koopman M, Zanen P, Kruitwagen CLJJ, Van Der Ent CK, Arets HGM. Reference values for paediatric pulmonary function testing: the Utrecht dataset. Respir Med. 2011;105(1):15-23.

26. Quanjer PH, Tammeling GJ, Cotes JE, Pedersen OF, Peslin R, Yernault JC. Lung volumes and forced ventilatory flows. Eur Respir J. 1993;6(Suppl 16):5-40.

27. Bianchi C, Baiardi P. Cough peak flows: standard values for children and adolescents. Am J Phys Med Rehabil. 2008;87(6):461-7.

28. Hull J, Aniapravan R, Chan E, Chatwin M, Forton J, Gallagher J, et al. Guideline for respiratory management of children with neuromuscular disease. Thorax. 2012;67:1-40.

29. Gibson GJ, Whitelaw W, Siafakas N, Supinski GS, Fitting JW, Bellemare F, et al. American thoracic society/European respiratory society ats/ ers statement on respiratory muscle testing. Am J Respir Crit Care Med. 2002;166:518-624.

30. Miller MR, Hankinson J, Brusasco V, Burgos F, Casaburi R, Coates A, et al. Standardisation of spirometry. Eur Respir J. 2005;26(2):319-38.

31. Kano H, Nakata H, Martin CF. Optimal curve fitting and smoothing using normalized uniform B-splines: a tool for studying complex systems. Appl Math Comput. 2005;169:96-128.

32. Hull J, Aniapravan R, Chan E, Chatwin M, Forton J, Gallagher J, et al. British Thoracic Society guideline for respiratory management of children with neuromuscular weakness. Thorax. 2012;67:11-40.

33. Hautmann H, Hefele S, Schotten K, Huber RM. Maximal inspiratory mouth pressures (PIMAX) in healthy subjects-What is the lower limit of normal? Respir Med. 2000;94:689-93.

34. Wijngaarde CA, Stam M, Otto LAM, Van Eijk RPA, Cuppen I, Veldhoen ES, et al. Population-based analysis of survival in spinal muscular atrophy. Neurology. 2020;94(15):e1634-44.

35. Hagenacker T, Wurster CD, Günther R, Schreiber-Katz O, Osmanovic A, Petri S, et al. Nusinersen in adults with $5 q$ spinal muscular atrophy: a noninterventional, multicentre, observational cohort study. Lancet Neurol. 2020;19(4):317-25.

36. Schoser B, Fong E, Geberhiwot T, Hughes D, Kissel JT, Madathil SC, et al. Maximum inspiratory pressure as a clinically meaningful trial endpoint for neuromuscular diseases: a comprehensive review of the literature. Orphanet J Rare Dis. 2017;12(1):52.

37. Kapur N, Deegan S, Parakh A, Gauld L. Relationship between respiratory function and need for NIV in childhood SMA. Pediatr Pulmonol. 2019;54(11):1174-80

38. Fauroux B, Aubertin G, Cohen E, Clément A, Lofaso F. Sniff nasal inspiratory pressure in children with muscular, chest wall or lung disease. Eur Respir J. 2009;33(1):113-7.

39. Suárez AA, Pessolano FA, Monteiro SG, Ferreyra G, Capria ME, Mesa L, et al. Peak flow and peak cough flow in the evaluation of expiratory muscle weakness and bulbar impairment in patients with neuromuscular disease. Am J Phys Med Rehabil. 2002;81(7):506-11.
40. Buyse GM, Goemans N, Van Den Hauwe M, Meier T. Effects of glucocorticoids and idebenone on respiratory function in patients with duchenne muscular dystrophy. Pediatr Pulmonol. 2013;48(9):912-20.

41. Steier J, Kaul S, Seymour J, Jolley C, Rafferty G, Man W, et al. The value of multiple tests of respiratory muscle strength. Thorax. 2007:62(11):975-80.

\section{Publisher's Note}

Springer Nature remains neutral with regard to jurisdictional claims in published maps and institutional affiliations.
Ready to submit your research? Choose BMC and benefit from:

- fast, convenient online submission

- thorough peer review by experienced researchers in your field

- rapid publication on acceptance

- support for research data, including large and complex data types

- gold Open Access which fosters wider collaboration and increased citations

- maximum visibility for your research: over $100 \mathrm{M}$ website views per year

At BMC, research is always in progress.

Learn more biomedcentral.com/submissions 